GRASAS Y ACEITES 71 (1)

January-March 2020, e344

ISSN-L: 0017-3495

https://doi.org/10.3989/gya.1169182

\title{
Waxes used as structuring agents for food organogels: A Review
}

\author{
C.C. Mandu ${ }^{a}$, D. Barrera-Arellano ${ }^{\text {b }}$, M.H.A. Santana ${ }^{a}$ and G.D. Fernandes ${ }^{\mathrm{b},} \otimes$ \\ ${ }^{a}$ Biotechnological Process Laboratory, School of Chemical Engineering, University of Campinas, Brazil. \\ ${ }^{\mathrm{b}}$ Fats and Oils Laboratory, Department of Food Technology, University of Campinas, Brazil. \\ Corresponding author: gabrieldfcac@hotmail.com
}

Submitted: 07 November 2018; Accepted: 14 March 2019; Published online: 14 January 2020

SUMMARY: Lipids are key ingredients in the human diet. Because of the manipulation and modification of lipids in the food industry, the amount of trans and saturated fat has been substantially increasing in industrialized products. At the same time, the number of studies demonstrating the harmful effects of these foods on human health has increased. Organogels arise as a promising alternative for replacing trans and saturated fat in processed foods. Among the main challenges of preparing an organogel is the difficulty of finding compatible and viable structuring agents in the food industry. Waxes have been studied for this purpose and are one of the most promising organogelators. This article brings a bibliographical review on the recent studies regarding the use of waxes as structuring agents for edible vegetable oils.

KEYWORDS: Foods; Lipid; Organogel; Structuring agent; Wax

RESUMEN: Ceras utilizadas como agentes estructurantes para organogeles de alimentos - Revisión: Los lípidos son ingredientes clave en la dieta humana. Debido a la manipulación y modificación de estos lípidos en la industria alimentaria, la cantidad de grasas trans y las saturadas ha aumentado sustancialmente en los productos industrializados. Al mismo tiempo, ha aumentado la cantidad de estudios que demuestran los efectos nocivos de estos alimentos en la salud humana. Los organogeles surgen como una alternativa prometedora para reemplazar las grasas trans y las saturadas en los alimentos procesados. Entre los principales desafíos de preparar un organogel está la dificultad de encontrar agentes estructurantes compatibles y viables en la industria alimentaria. Las ceras se han estudiado para este propósito y son uno de los organogeladores más prometedores. Este artículo presenta una revisión bibliográfica de los estudios recientes sobre el uso de ceras como agentes estructurantes para aceites vegetales comestibles

PALABRAS CLAVE: Agente estructurante; Alimentos; Cera; Lipidos; Organogel

ORCID ID: Mandu CC https://orcid.org/0000-0002-9152-3565, Barrera-Arellano D https://orcid.org/0000-0002-82178392, Santana MHA https://orcid.org/0000-0002-2258-4911, Fernandes GD https://orcid.org/0000-0001-6099-3225

Citation/Cómo citar este artículo: Mandu CC, Barrera-Arellano D, Santana MHA, Fernandes GD. 2020. Waxes used as structuring agents for food organogels: A Review. Grasas Aceites 71 (1), e344. https://doi.org/10.3989/gya.1169182

Copyright: (C2020 CSIC. This is an open-access article distributed under the terms of the Creative Commons Attribution 4.0 International (CC BY 4.0) License. 


\section{INTRODUCTION}

A series of problems is currently associated with the use of traditional fats in modern human food, mainly related to the presence of high contents of saturated and trans fatty acids (Yilmaz and Oğütcü, 2015). Over the last few years, studies have shown that diets with high intakes of this type of fat have negative consequences for health, contributing to several diseases in humans but mainly increasing the risk of developing cardiovascular diseases and diabetes, which significantly reduce the quality of life and can lead to death (Hunter et al., 2009). Public organizations around the world are implementing regulations to restrict and inhibit the use of this type of fat in the food industry. Trans fat has already been banned in some countries and its use has been restricted in others (Executive Order No. 160, 2003; Oviedo, 2010; Medical Officer of Health; FDA Federal Register - 68 FR 41433 July 11, 2003; New York City Health Code, 2006; Resolutions RDC No. 359 - Technical Regulation of Portions of Packaged Foods for the Purposes of Nutrition Labeling and RDC No. 360 - Technical Regulation on Labeling Nutrition of Packaged Food, incorporating the norms approved in the Mercosul to the national legal order - Anvisa, 2003ab).

However, in order to maintain texture and palatability in the food industry, the amount of saturated fats has considerably increased, which has also been shown to be incompatible with human health. Saturated fatty acids also have their recommended reductions in the dietary guidelines of several countries (Wang and Rogers, 2015; USA, 2016). These actions have required researchers and industries to search for alternatives to this type of fat in processed foods (Penteado et al., 2018). In this context, in recent years one of the research themes in evidence is edible organogels as substitutes for saturated and trans-fat in foods. Organogels are semi-solid systems, predominantly high in unsaturated fatty acids, structured by a three-dimensional network formed by a structuring agent. Oil by itself does not have the sufficient structure to confer texture and palatability to foodstuffs in a similar way to the fats with high levels of trans and saturated fatty acids, and so their direct application in several processed foods is not viable. Recently studies have shown that organogels can present technological performance which is very similar to a solid fat, making it possible to use them in some food applications (Hwang et al., 2016; Kouzounis et al., 2017; Chaves et al., 2018).

In food, the main challenge is to identify the best oil structuring agent that are food grade, easily available, affordable, and especially able to structure liquid lipids at relatively low concentrations and produce organogels with fat-like physical characteristics for food purposes. This challenge versus the real necessity to reduce saturated fats in the food industry has exponentially increased research with the prospect for new structuring agents (Singh et al., 2017). Waxes appeared among the several structuring agents studied and appear to be among the most promising ones (Tavernier et al., 2017).

Waxes are found on the surface of leaves, seeds and fruits. Their main function is the protection of the plant in relation to the loss and absorption of water, gases and biological volatile compounds. They have a very particular lipid composition, commonly known by their long-chain fatty acids esterified with long-chain alcohols. They are generally classified according to their origin, whether animal, vegetable or mineral. Among the benefits of using natural wax as a structuring agent for oil is its recognition as a safe additive for use in food by the FDA (Food and Drug Administration) - Generally Recognized as Safe (GRAS) - FDA. Waxes are able to structure in a three-dimensional network with high capacity to bind with oil and can form gels at relatively low concentrations (Tavernier et al., 2017). The objective of this study was to collect a selection of articles from recent years which explore the types and diversity of waxes used as structuring agents for application in food grade organogels as a bibliographical review.

\subsection{Fundamentals and mechanisms for the establishment of organogels}

Regarding the concept of gels, based on material science, a more sensible definition should be limited to systems that possess following phenomenological characteristics: (1) consist of two or more components, of which the major component is liquid; (2) the minor components must be solid or semisolid. Other very important features that contribute to the concept of gels are presented through dynamic mechanical properties. Rheologically, the energy storage module, elastic module G' exhibits a steep plateau extending to times of the order of seconds and a module of loss, viscous module G", which is considerably smaller than storage modules. The most important is the solid gel character, and that the deformations be elastic or recoverable (Terech and Weiss, 1997; Almdal et al., 1993). A pseudoplastic flow is most common for food gel formulations. These compounds show a gradual decrease in their apparent viscosity as the shear stress increases. Since viscosity is an expression of fluid resistance to flow, the higher the viscosity, the higher the resistance. The pseudoplastic solutions present behavior resulting from a structure in a fully organized network (Guedes, 2012).

An organogel is generally prepared by heating oil and one or more solid structuring agent until the melting point of all the components is overcome and complete homogenization occurs. The solution is then cooled until the gelling temperature 
is reached. The resulting material is a gel or jelly depending on its hardening ability or thickening, but the formal description and classification are based on the rheological properties as previously mentioned (Guedes, 2012).

Different approaches have been studied as potential for the structuring of lipid-based organogels in order to reduce the amount of saturated and transfat. Structures may vary widely, but in relation to structural organization they fall into the categories of crystalline particles, polymer chains, particulate networks, and liquid crystal (Sintang et al., 2017). Because of this, recent studies describe the use of various components for structuring oils. These structuring agents would be capable of acting on lipid systems by modulating characteristics such as thermal behavior, polymorphic stability and microstructure. These effects would consequently be observed at a macroscopic level, such as appearance, rheology and consistency (Chaves et al., 2018). The structuring agents commonly used include fatty acids, fatty alcohols, mixtures of fatty acids and fatty alcohols, mixtures of phytosterols/orizanols, sorbitan monostearate, mixtures of lecithin, sorbitan tristearate, celluloses, methylcelluloses and waxes (Godoi et al., 2017; Rogers et al., 2009; Totosaus et al., 2016). In addition, the blend of some ingredients may result in a synergistic effect on the structuring potential of the oils when compared to the use of pure materials (Chaves et al., 2018). In conventional lipid structuring when a complex mixture of triacylglycerol is subjected to cooling, the molecules with high melting points start the nucleation event by interacting with each other through non-covalent forces. After the nucleation, these formed nuclei aggregate and form agglomerates that transform into large structures which finally reach the macroscopic three-dimensional crystalline network. This structure of plastic fats characterizes the conventional crystallization process based on triacylglycerols (Figure 1A). The unconventional structuring process, explored in the organogels, deals with lipid systems with the mostly highly-unsaturated fatty acids which are structured in gels through continuous networks of small molecules (structuring agents) that interact in different ways to trap the liquid fraction (Figure 1B) (Chaves et al., 2018).

Generally, two routes can be found for unconventional lipid structuring: solubility induction and polarity induction. The definition of these routes depends basically on the structuring agent, the oil and the process applied. The solubility induced pathway occurs mainly for high melting point structuring agents. With a reduction in temperature super-saturation of the system occurs, forming small crystals that are organized in a self-structured network and trap the oil into a gel format. The polarity-induced pathway occurs for amphiphilic builders as in the case of phospholipids, where the fractions of similar polarity, for example the polar heads of the phospholipids, are associated, forming a self-structuring network of structuring agents that trap the oil into a gel form. These routes promote the formation of so-called structuring elements that have the action of building blocks in structuring the three-dimensional network of the organogel. The size and shape of these structuring blocks and the interaction between them will determine the final macrostructure of the product and therefore its application properties (Pernetti et al., 2007).

According to Marangoni and Garti, 2011 the structuring of gels can occur in 5 different ways depending on the structuring agent employed.

Crystalline particles: Crystaline particles are systems formed through the route of solubility. Crystalline particles formed are able to trap the oil within its crystals causing gelation. The size, shape, and interaction of these crystals will determine the mechanical properties of the organogel. This type of structuring can be activated with diacylglycerols, monoacylglycerols, fatty acids, waxes, and sorbitans, which are widely used in foods (Marangoni and Garti, 2011).

Crystalline fibers: Crystaline fibers are self-assembled networks through crystalline fibers which are hundreds of microns in length. Structuring agents that can cause this type of structuring are those known as low-molecular weight builders such as phytosterols with oryzanol, 12-hydroxystearic acid and ricinoleic acid. They generally use the polarity route for their structuring in oils (Marangoni and Garti, 2011).

Polymer chains: Through the polarity route, the polymers promote the gelation of a medium. They may be gels formed by covalent bonding or gels formed by self-assembly. The great majority of studies in the literature dealing with this type of structuring are for aqueous systems and still little used for oils (Marangoni and Garti, 2011).

Particulate Chain: Particulate chains formed by the solubility route are lipid-based products structured by a dispersion of a large number of inert particles, such as silica, in a continuous phase. They can be solid (suspension) or liquid (emulsion). The structuring agent must be present in a sufficiently high concentration in order to promote gelation. The disadvantage is that it requires a high number of structuring agents which is still not favorable for food application (Marangoni and Garti, 2011).

Liquid crystals: Lipid crystalline occurs with the formation of organogel through a semi-crystalline scaffold formed inside the oil with gel properties through the polarity route. These scaffolds are formed by the crystalline mesophasic liquid which are substances in the intermediate state between liquid and solid (Marangoni and Garti, 2011).

These structuring agents are differentiated by their molecular mass, such as high or low, where 


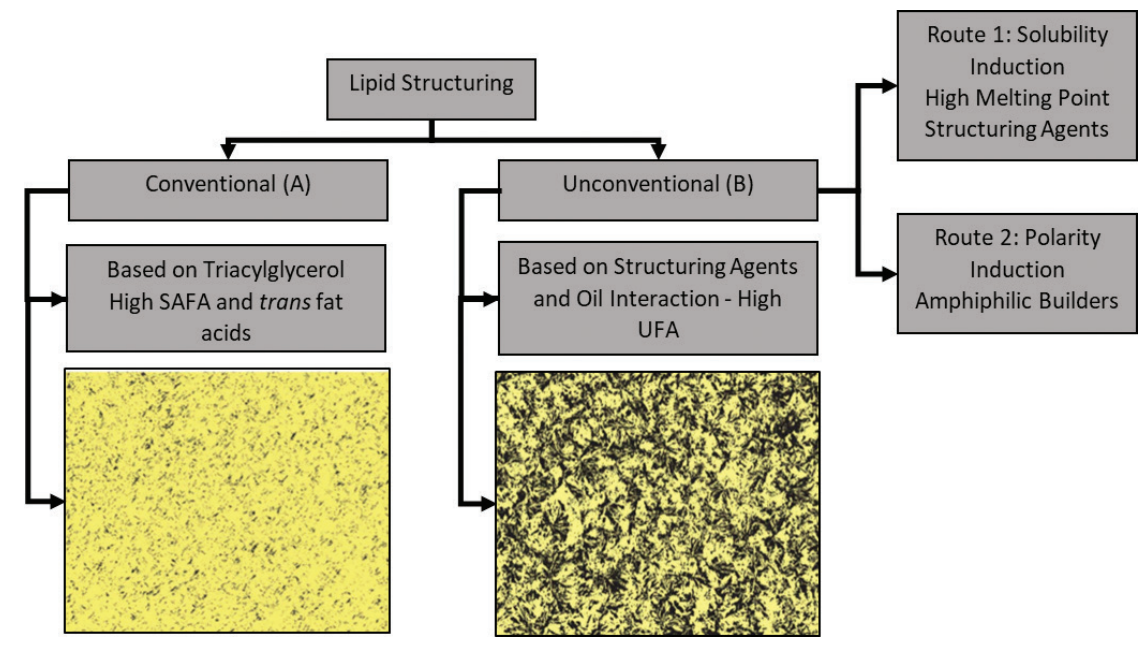

FIGURE 1. Lipid microstructure through the conventional process A, and unconventional B, adapted from (Chaves et al., 2018).

molecules with low molecular weight are those with less than $3000 \mathrm{Da}$. They can be used for example to trap liquid oil inside its self-assembled structure by promoting a macroscopic structure (Chaves et al., 2018). The most common structuring agents for food applications (Figure 2) and their structuring mechanisms are briefly described below.

These structuring agents can be found in their purified form or as commercial mixtures commonly applied as food ingredients. For instance, saturated triacylglycerols can be found as hard fat or fullyhydrogenated oils, mono and diacylglycerols, as well as lecithin and sorbitan stearates, and can be found as food emulsifiers and/or stabilizers. On the other hand, long-chain fatty acids and alcohols plus their esters (wax esters) can be found in natural waxes, along with some natural hydrocarbons which can also contribute to the structuring effects.

As previously mentioned, natural waxes are one of the main structuring agents applied in food organogels. Wax organogels are the central focus of this review, thus, the physicochemical characteristics of natural waxes, their structuring properties, as well as their applications will be extensively discussed during the next sections.

\section{CHEMICAL COMPOSITION OF WAXES}

Waxes are considered natural lipidic mixtures and can be differentiated by the proportion of the following compounds: n-alkanes or hydrocarbons (HC), free fatty acids (FFAs), free fatty alcohols (FAL), wax esters (WEs), ketones and sterols (Doan et al., 2017). Waxes with different chemical compositions have different melting points and, therefore, different crystallization behaviors and consequently different oil structuring abilities (Doan et al., 2017). Therefore, to understand the behavior of a wax as a structuring agent for organogel, a better understanding of its chemical composition is essential (Doan et al., 2017).

The chemical composition of the wax is closely linked with its origin and extraction methodology, but solid information about the proportion of its constituent and chain size are still deficient (Doan et al., 2017). As waxes are derived from natural sources their composition and characteristics are intrinsic to each material (Chaves et al., 2018).

In 2017, Doan et al., carried out a characterization study of the main waxes applied for food organogels and the differences among them. Among the most extensively studied waxes are those from rice, sunflower, bee, candelilla, carnauba and berry wax (Doan et al., 2017). Carnauba wax is derived from the leaves of the palm tree, Copernicia cerifera. The wax of candelilla is obtained from the leaves of the Candelilla shrub, Euphorbia cerifera. Rice bran wax (Oryza sativa) and sunflower wax (Helianthus annuus) are obtained through the winterization process of their respective oils (Chaves et al., 2018). Berry wax is derived from the fruit peels of the Rhus verniciflua tree, native to China. Beeswax is of natural origin and produced by bees during the formation of hives (Doan et al., 2017).

For the chemical characterization the authors have previously characterized the major lipid classes such as hydrocarbons, free fatty acids, free fatty alcohols and wax esters through HPLC analysis. In this study ketones and sterols were not evaluated because of their minor participation in the composition of wax.

During the following characterization steps, the authors have determined the composition of each lipid class. Regarding the wax esters, the compositions of esterified fatty alcohols and fatty acids were studied, indicating that the chain lengths range from 32 to 68 carbon atoms. The esters were formed by a medium/ long-chain fatty acid bonded with a long-chain fatty 

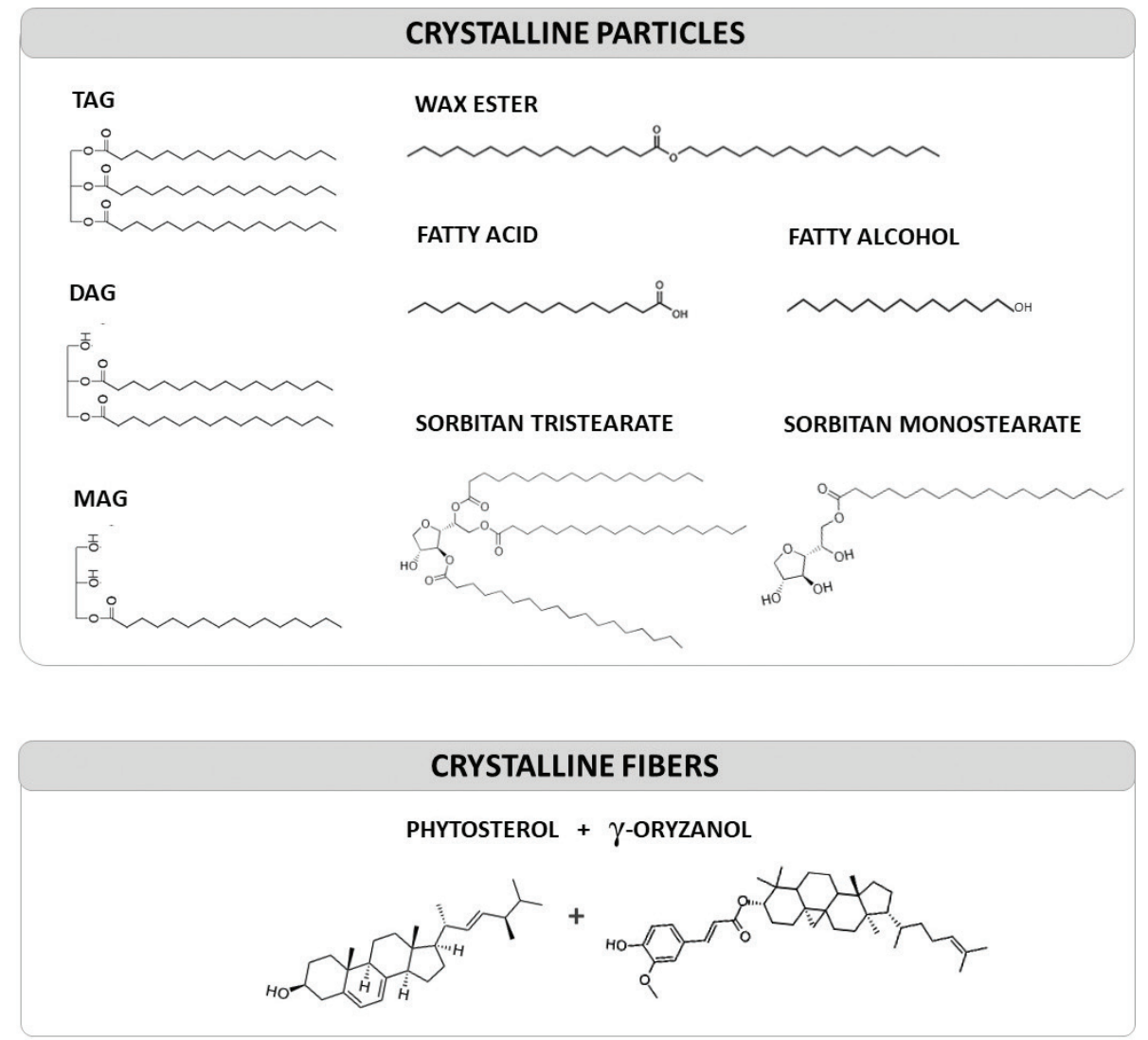

FIGURE 2. Scheme of the molecular chains of the main structuring agents for organogels for food applications, according to their structuring behavior, adapted from (Pernetti et al., 2007).

alcohol. The hydrocarbon fraction was present only in beeswax and candelilla wax. The free fatty acid portions of the natural waxes constitute a large part of components having an alkyl chain of 16 and 32 carbon atoms, while the free fatty alcohol chains vary from 24 to 34 carbons (Table 1) (Doan et al., 2017).

Sunflower wax, rice bran wax, and berry wax may be considered one-component waxes. This happens because for sunflower waxes and rice bran the composition is mostly $(>90 \%)$ wax esters. And for berry wax the composition is mostly free fatty acids ( 95\%) (Doan et al., 2017). The esters of sunflower wax are composed predominantly of chains from 44 to 50 carbons and their major free fatty acids have chains from 16 to 24 carbons, also confirmed by Kanya et al., (2007)

Rice bran wax also contains major free fatty acids from 16 to 24 carbons, also confirmed by Kanya et $a l$. , (2007). Their ester wax chains were from 44 to 50 carbons, which is a similar composition to sunflower wax (Kanya et al., 2007; Doan et al., 2017). In berry wax, palmitic and stearic acid are the major free fatty acids (approximately 90\%) (Doan et al., 2017).

The other waxes can be considered of a less uniform composition. Carnauba waxes from different origins, one commercial wax from Brazil and one wild sample, do not show significant differences in their compositions. Both have wax esters as the main component (61\% on average) and free fatty alcohols (33\% on average) as the second component. For both samples, the major fatty acid in the wax ester molecules was $\mathrm{C} 24: 0$ and the major fatty alcohol was C32:0 (Doan et al., 2017).

The waxes from bees and candelilla were those that have a greater amount of long-chain hydrocarbons. Beeswax is among the most heterogeneous waxes, but, wax esters are still the predominant ones $(\sim 58 \%)$ followed by hydrocarbons $(\sim 26 \%)$. The hydrocarbons have C27, 29 and 31 chains. Similar observations were reported by Toro-Vazquez in 2013. The fatty acid fraction of wax esters was basically of palmitic acid (C16:0, 80\%), while in the fatty alcohol fractions, chains from 18 to 32 carbons were found. For the free fatty acids, they varied from 12 to 34 carbons and constitute approximately $95 \%$ of their composition, with predominant chains from 16 to 24 carbons and the results are compatible with those of Tulloch, (1975). The portion of free fatty alcohols was composed of C40 to 48 alkyl chains in beeswax (Doan et al., 2017).

The candelilla wax is the only one among the evaluated waxes that has hydrocarbons as it main 
TABle 1. Average of the main composition of waxes, adapted from Doan et al., 2017. Only Average is described in this table. Standard deviation and replicates are completely described in the original article

\begin{tabular}{|c|c|c|c|c|c|c|c|}
\hline & $\begin{array}{l}\text { Rice Bran } \\
\text { Wax }\end{array}$ & $\begin{array}{l}\text { Sunflower } \\
\text { Wax }\end{array}$ & $\begin{array}{l}\text { Bees } \\
\text { Wax }\end{array}$ & $\begin{array}{c}\text { Candelilla } \\
\text { Wax }\end{array}$ & $\begin{array}{c}\text { Carnauba } \\
\text { Brazilian Wax }\end{array}$ & $\begin{array}{l}\text { Carnauba } \\
\text { Wild Wax }\end{array}$ & $\begin{array}{l}\text { Berry } \\
\text { Wax }\end{array}$ \\
\hline \multicolumn{8}{|c|}{ Free Components } \\
\hline \multicolumn{8}{|c|}{ Hydrocarbon (HC, $\%$ of fraction) } \\
\hline $\mathrm{C}_{27}$ & $\mathrm{ND}^{\mathrm{a}}$ & ND & 40.28 & 0.15 & ND & ND & ND \\
\hline $\mathrm{C}_{29}$ & ND & ND & 25.63 & 6.26 & ND & ND & ND \\
\hline $\mathrm{C}_{31}$ & ND & ND & 18.05 & 82.48 & ND & ND & ND \\
\hline $\mathrm{C}_{33}$ & ND & ND & 3.12 & 7.68 & ND & ND & ND \\
\hline \multicolumn{8}{|c|}{ Fatty Acids (FFA, $\%$ of fraction) } \\
\hline $\mathrm{C}_{16}$ & 20.76 & 33.18 & 30.11 & 17.84 & 16.17 & 28.57 & 82.13 \\
\hline $\mathrm{C}_{18}$ & 5.54 & 20.42 & 6.84 & 1.90 & 17.84 & 5.38 & 11.26 \\
\hline $\mathrm{C}_{20}$ & 8.70 & 22.12 & 1.74 & 1.31 & 10.57 & 9.14 & 0.39 \\
\hline $\mathrm{C}_{22}$ & 17.52 & 9.73 & 4.33 & 1.60 & 6.28 & 5.50 & ND \\
\hline $\mathrm{C}_{24}$ & 28.33 & 4.00 & 27.80 & 0.64 & 15.47 & 13.37 & ND \\
\hline $\mathrm{C}_{26}$ & 3.36 & 2.26 & 6.55 & 0.90 & 6.17 & 5.25 & ND \\
\hline $\mathrm{C}_{28}$ & 3.34 & 2.85 & 7.20 & 3.13 & 10.58 & 9.78 & ND \\
\hline $\mathrm{C}_{30}$ & 3.03 & 0.99 & 6.60 & 31.38 & 4.70 & 4.50 & ND \\
\hline \multicolumn{8}{|c|}{ Fatty Alcohols (FAL, $\%$ of fraction) } \\
\hline $\mathrm{C}_{24}$ & 25.30 & 25.25 & 12.01 & 1.77 & ND & ND & ND \\
\hline $\mathrm{C}_{26}$ & 26.15 & 24.11 & 9.46 & 4.53 & ND & ND & ND \\
\hline $\mathrm{C}_{28}$ & 16.16 & 17.74 & 12.95 & 11.48 & 6.38 & 5.67 & ND \\
\hline $\mathrm{C}_{30}$ & 15.39 & 10.46 & 29.23 & 42.28 & 13.94 & 13.22 & ND \\
\hline $\mathrm{C}_{32}$ & 9.47 & 5.92 & 20.40 & 14.57 & 65.39 & 68.29 & ND \\
\hline $\mathrm{C}_{34}$ & 4.70 & ND & 3.94 & 2.83 & 11.17 & 10.95 & ND \\
\hline \multicolumn{8}{|c|}{ Wax Ester Components (WE) } \\
\hline \multicolumn{8}{|c|}{ Fatty Acids Moieties } \\
\hline $\mathrm{C}_{16}$ & 8.63 & 4.89 & 80.27 & 34.16 & 15.16 & 19.35 & 79.89 \\
\hline $\mathrm{C}_{18}$ & 4.97 & 4.84 & 9.54 & 17.44 & 16.69 & 19.00 & 13.25 \\
\hline $\mathrm{C}_{20}$ & 22.95 & 48.65 & 0.51 & 6.31 & 16.02 & 13.06 & ND \\
\hline $\mathrm{C}_{22}$ & 26.75 & 24.14 & 0.43 & 10.87 & 12.19 & 9.47 & ND \\
\hline $\mathrm{C}_{24}$ & 27.83 & 5.87 & 0.47 & 1.20 & 22.38 & 18.65 & ND \\
\hline \multicolumn{8}{|c|}{ Fatty Alcohols Moieties } \\
\hline $\mathrm{C}_{18}$ & 2.80 & 1.82 & 2.93 & 20.70 & 13.69 & 21.48 & 66.02 \\
\hline $\mathrm{C}_{22}$ & 6.92 & 9.48 & ND & ND & 3.08 & 2.55 & ND \\
\hline $\mathrm{C}_{24}$ & 29.46 & 34.41 & 25.19 & 2.05 & 3.61 & 4.41 & 8.77 \\
\hline $\mathrm{C}_{26}$ & 23.94 & 30.07 & 14.20 & 8.18 & 1.73 & 1.46 & 3.82 \\
\hline $\mathrm{C}_{28}$ & 13.7 & 12.15 & 13.45 & 18.72 & 3.15 & 1.60 & 3.32 \\
\hline $\mathrm{C}_{30}$ & 11.16 & 4.01 & 26.12 & 26.64 & 11.95 & 10.37 & 3.05 \\
\hline $\mathrm{C}_{32}$ & 5.31 & 2.20 & 13.57 & 7.99 & 51.74 & 47.89 & 3.53 \\
\hline \multicolumn{8}{|c|}{ Total Fractions } \\
\hline $\mathrm{HC}$ & 0.29 & 0.17 & 26.84 & 72.92 & 0.41 & 0.16 & 0.03 \\
\hline FFA & 6.00 & 3.29 & 8.75 & 9.45 & 6.80 & 6.32 & 95.7 \\
\hline FAL & 0.22 & 0.32 & 6.42 & 2.20 & 30.74 & 34.53 & 4.24 \\
\hline WE & 93.49 & 96.23 & 58.00 & 15.76 & 62.05 & 58.99 & 0.02 \\
\hline
\end{tabular}

ND - non described by the authors 
component $(\sim 72 \%)$, followed by wax esters $(\sim 15 \%)$. Around of $82 \%$ of this hydrocarbon fraction was of 31 carbons, which is a very particular characteristic of candelilla wax. Palmitic acid was the main fatty acid in the wax ester fraction, while C30:0 was the main fatty alcohol in this fraction. Its portion of free fatty alcohols was composed mainly of C16:0 and C30:0 (Doan et al., 2017). Due to the differences in chemical composition, the different waxes show different behaviors when added to organogels. This structuring behavior will be extensively discussed in the following chapters. These compiled composite data are presented in Table 1.

\section{WAXES AND STRUCTURING}

The physical properties of a wax organogel are not only the result of the wax and oil composition but are also influenced by the interactions between the components of the structuring agents and the crystals formed by them. The number of these interactions is directly proportional to the number and structure of the crystals that form the self-structured crystalline network resulting in the alteration of the rheological properties of the gel (Doan et al., 2017).

Through their components, the waxes naturally form crystals with the morphology of stems or platelets, resulting in gels of stronger structure. They use the route of solubility in this process. Due to their high melting point, when the system is cooled, the wax components crystallize into small platelets forming a self-sustaining network. Some partially polar fractions of the wax constituents contribute to the stability of the system through the polarization path but are not the key points in this case (Doan et al., 2017).

The strength, consistency, fragility and stability of the wax-based organogels can be governed by changes in the concentration of wax, the type of oil used, the rate of cooling and shear during the preparation of the organogel. A modification in these factors will alter the structuring agent/oil interaction leading to a change in the gelling properties. To exemplify these differences, in 2017, Doan et al., carried out comparative studies of gels made up of 7 different waxes in rice bran oil. The waxes were used in different proportions according to their minimum gelation capacity: $1.0 \%$ for sunflower, candelilla and berry waxes; $1.5 \%$ for beeswax, $5 \%$ for rice bran wax, $2 \%$ for imported carnauba wax and $4 \%$ for Brazilian carnauba wax. The behavior of all gels was compared through analysis of microstructure, rheology, DSC (differential calorimetry scanning), and XRD (X-ray diffraction) (Doan et al., 2017). These analyses are the most frequently mentioned and cited in the characterization of organogels in the literature. The first observation made by the authors, through DSC analysis, was that the predominant components in the composition of the wax govern crystallization. In the case of rice bran and sunflower wax, the wax esters crystallized at a temperature considered to be very high (approximately $50{ }^{\circ} \mathrm{C}$ ). For beeswax the most relevant peak is also wax esters at approximately $40{ }^{\circ} \mathrm{C}$, followed by the second largest component of beeswax, the hydrocarbons at approximately $30{ }^{\circ} \mathrm{C}$. For the organogel with candelilla wax the strongest crystallization peak occurred at approximately $40{ }^{\circ} \mathrm{C}$ due to the large presence of hydrocarbons (mainly $82.48 \%$ of the hentriacontane, C31). A smaller peak appeared at approximately $43^{\circ} \mathrm{C}$, probably due to the portion of esters in the wax. The organogels with Brazilian and wild carnauba wax (nationality not mentioned clearly) presented similar crystallization due to similar chemical compositions. However, the organogel with imported carnauba wax exhibited only a minor peak at approximately $33{ }^{\circ} \mathrm{C}$ due to the presence of free fatty alcohols. The organogel with berry wax obtained crystallization at the lowest temperature, with the first peak at around $10{ }^{\circ} \mathrm{C}$, probably due to the presence of $82 \%$ of medium-chain free palmitic acid (C16:0) in its composition (Doan et al., 2017).

From the rheology analysis, it was observed that the organogels prepared with sunflower, bee, candelilla and berry waxes presented the largest $G^{\prime}$ modulus (elastic modulus) and critical stress compared to the rice bran, Brazilian and wild carnauba wax organogels. The organogels with candelilla and berry wax showed the highest consistencies and lowest yield stress. In the group of gels considered to be weaker, the organogel with rice bran wax was the one that presented higher $G^{\prime}$ but less critical stress compared to the gels of carnauba wax. As expected, the carnauba wax gels obtained very similar weakness, regardless of their minimum gelling concentration (4\% for Brazilian carnauba and $2 \%$ for imported carnauba) (Doan et al., 2017).

In the X-ray diffraction analysis, all wax organogels (except berry wax) showed peaks at high diffraction angles, which are indicative of orthorhombic crystal structures. All wax-based organogels showed peaks in the low-angle region, providing evidence of lamellar packaging. A difference in intensity between high and low angle peaks (as is the case of the organogel of candelilla) was also mentioned by the authors as the result of a strong anisotropy in the crystal growth rates between the vertical directions to the lamellar and the different directions inside the lamellar plane. The Van der Waals interaction between the long hydrocarbon chains and the ester group chains (the molecular interactions in the lamellar plane) are much stronger than the molecular interactions across the terminal $\mathrm{CH}_{3}$ groups. This mechanism leads to the appearance of stem or platelet morphologies, which are desirable for the formation of a strong organogel. This is confirmed by the strong gelling properties of sunflower, candelilla, bee and berry wax in rice bran oil, which 

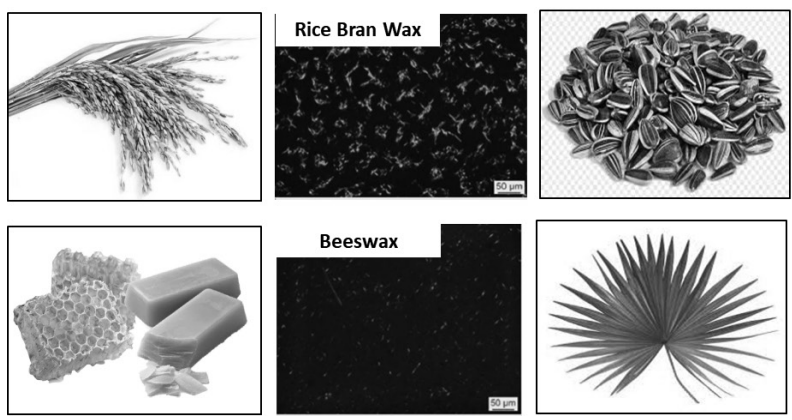

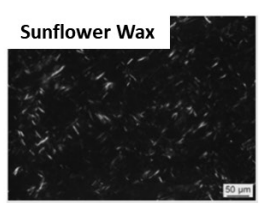

Carnauba Wax

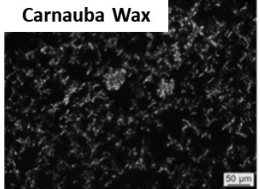

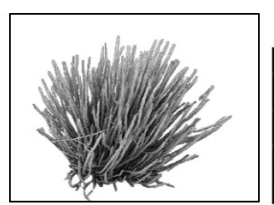

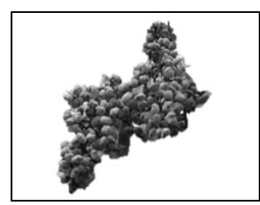

Candelilla Wax

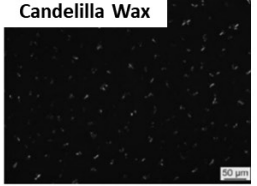

Berry Wax

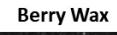

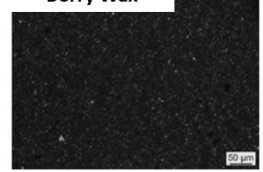

FIGURE 3. Microstructure of structured organogels with different waxes, adapted from (Doan et al., 2017).

exhibited small needle-like crystals (Figure 3) (Doan et al., 2017).

The activity of the crystallization and gelation of waxes is usually explained by the difference in their composition. The presence of wax esters resulted in a strong but brittle gel, which is expressed in a high storage modulus and flow stress of the organogels and their waxes. Hydrocarbons and free fatty acids contribute to the consistency and stability of waxbased organogels (high critical stress and high consistency). However, chain length needs to be taken into account because the shorter the chain fatty acids ( $<16$ carbons) the more they result in the crystallization of wax at low temperatures, which may limit its application in food applications, similar to what happens in berry wax organogels. Free fatty alcohols also make an important contribution to the structuring of wax organogels. However, they have strong hydrocarbon linkages and may entail gelation. The results from the studies provide important information about the need to know and understand the role of each component of the waxes in the structuring of oils, which should be explored to select a wax with desirable properties for application in food (Doan et al., 2017).

\section{APPLICATIONS OF WAX ORGANOGELS IN FOODS}

\subsection{Margarine}

In a study in 2016, Hwang et al., used 3 different types of waxes (candelilla, sunflower and rice bran) as soybean oil scrapers for margarine application. It was discovered in a previous study by the same group that sunflower wax, cadelilla and rice bran are the most promising as structuring for soybean oil and therefore were selected for this study (Hwang et al., 2016). Soybean oil was used because of its wide availability, low cost and high polyunsaturated content. In this study margarines made with organogels from the three different waxes had characteristics such as firmness, melting behavior and spreadability compared to commercial margarine. The authors started with the evaluation of organogels. The consistency of all the gels was measured in a texturometer and the following order of firmness was determined: rice bran wax, candelilla wax and sunflower wax in soybean oil. The authors have also observed significant differences for gels of the same wax obtained from different suppliers, noting that the difference in composition and purity of the wax directly influences the consistency and firmness of the organogel.

For margarine production, the fatty aqueous phase was first prepared separately and heated to the complete melting of the lipid phase. The emulsion was then formed by agitation and cooled to below the melting point of its fatty phase. The main results presented in this study were that the margarine formulated with an organogel of sunflower wax and soybean oil obtained a higher value of firmness and was considered the most successful organogel. The margarine formulation with candelilla wax organogel showed phase separation after the formation of the emulsion and therefore did not have its texture evaluated. The authors believed that the emulsifiers used in the margarine formulation may be incompatible with candelilla wax, thus interfering in the stability of the emulsion. They suggest that for the use of this wax in margarine formulations the emulsifiers should be replaced with compatible ones. Rice bran wax did not allow margarine to achieve adequate consistency and showed the least firmness.

Even after forming stable and consistent gels, most of the wax organogels studies by Hwang and coworkers (2016) were not effective in the formation of margarine with compatible characteristics to commercial margarines due to their interactions with the other components of the formula. Therefore, the author compared the best results of the margarines formulated with sunflower wax to margarines produced with partially hydrogenated soybean oil (18-30\%), the most common structuring agent fat applied in industrial margarine production. After application to the margarine formulation, the wax organogels had slight decreases in firmness over margarine prepared with partially hydrogenated soybean oil. This result provides important information in terms of hardness characteristics, about 
$2-6 \%$ sunflower wax can replace $18-30 \%$ partially hydrogenated soybean oil in a margarine formulation. Waxes are considered much more suitable for the diet when compared to partially hydrogenated oil. Firmness results were also compared with commercial products like spreads and margarines. The results indicated that sunflower wax gels $(2 \% \mathrm{w} / \mathrm{w})$ were effective in achieving the firmness and consistency of commercial products. The author also suggested that gels with higher amounts of wax can be produced to achieve the consistency of harder commercial margarines.

In addition, the analyses of DSC, SFC and drop point were applied to margarine formulations with organogel structured with sunflower wax (more promising results according to the firmness analysis). The dropping point analysis showed that margarine formulated with wax organogel $>2 \%$ wax had a higher melting point than commercial margarines and spreads. This dropping point increased as the concentration of wax in the organogel was increased. Based on the DSC analysis they concluded that the highest melting point of margarine containing sunflower wax organogel was due to the higher melting point of the wax present in that margarine. In solid fat content (SFC) analyses, margarine samples prepared with sunflower wax obtained slightly higher values for solids than margarine prepared with hydrogenated soybean oil, mainly at $35^{\circ} \mathrm{C}$, which is the human body temperature that directly implies the sensorial characteristic of fusion in the mouth. Even so, the author does not clarify how this interferes with sensory quality and suggests that a sensory panel be made for future studies. The study concluded that sunflower wax organogels in soybean oil have the potential for total substitution of trans fats and / or saturated fats in margarines and spreads (Hwang et al., 2016).

\subsection{Ice creams}

Typically, ice creams have about $10-14 \%$ fat in their formulations, of which $60-70 \%$ are commonly composed of saturated fatty acids. Banupryia et al., (2016) studied the partial and total substitution of milk fat by sunflower oil organogels structured with rice bran wax in ice cream. Ice creams with $10 \%$ fat phase were prepared and five different proportions of milk fat substitution were evaluated $(0 \%$ - control, $2.5 \%, 5 \%, 7.5 \%$ and $10 \%$ - total substitution). Sunflower oil and rice bran wax were used to prepare the organogel in a ratio of 90 and $10 \%$, respectively. After preparation, the organogel was added as the oily phase in the different ratios mentioned above with respect to milk fat. The authors showed that the substitution of organogel by up to $100 \%$ of total fat did not change parameters such as $\mathrm{pH}$ or acidity, important parameters that interfere in the capacity of aeration of ice creams. Regarding viscosity, the range obtained a considerable variation of $60 \mathrm{cP}$ $(100 \%$ organogel) to $66 \mathrm{cP}(100 \%$ milk fat $)$. The addition of the organogels as the fatty phase in the ice cream produced a reduction in viscosity and consequently in the overrun, in proportion to the added amount. However, for substitutions of up to $50 \%$ milk fat by organogels the differences were insignificant (Banupryia et al.,2016).

During the same period, the research group presented a very similar study to the previous one, replacing sunflower oil with linseed oil. The authors emphasize the health benefits related to the product, since linseed oil has high levels of alpha linolenic acid (C18:3, Omega3), which contribute directly to the reduction of cardiovascular diseases, arterial problems, tumors and low triglyceride levels in the blood. The researchers presented the concept that the cost of producing ice cream with organogel from linseed oil with rice bran wax was higher than the formulation made with milk fat, basically due to the cost of the ingredients. Regarding the physicochemical characteristics, it was concluded that the substitution can be made up to a maximum of $25 \%$ of the total fat of the ice cream formulation. Thus, it is believed that the industry can use organogels in ice cream preparations as partial substitutes for fat and consumers can be served healthier products with the same product quality (Banupryia et al., 2016).

In 2013, Botega and co-workers developed formulations of ice cream with different wax organogels, high oleic sunflower oil with carnauba, candelilla and rice bran waxes using milk fat as a control. In addition, they investigated the influence of emulsifiers, fat concentration and process variations on the final quality of the ice cream with organogels. In the production of ice cream, emulsifiers are essential in the formation of appropriate lipid structures. The correct distribution of structuring agents and emulsifiers ensures a soft texture on the palate as well as good quality and melting characteristics. This is achieved through the perfect emulsification and structuring of the oily, aqueous and air phases, leading to a soft product that melts with the desired uniformity and speed in the mouth,

Thus, as the ice cream has both emulsion (emulsified droplets) and foam (emulsified air) properties, the nature and quality of emulsifiers employed are important factors for the success of a formulation. In the study, the authors emphasized the evaluation of microstructure and melting curves of the ice cream. For the wax organogel formulations, the emulsifiers, which are basically mixtures of saturated mono and diglycerides $(\sim 80 \%)$ and polysorbate $80(\sim 20 \%)$, directly interfere in the stability, melting rates and fat aggregation and therefore should be carefully tested and selected when the oil phase changes. The size and shape of the crystals formed by the wax during the structuring of the organogel may lead to synergistic and beneficial crystallization in the presence 
of emulsifiers but may also have a detrimental effect if not correctly selected. For this reason, an evaluation of the compatibility and synergy of crystals formed between all the structuring agents is necessary. The authors presented different possibilities in the freezing process for the formulations in order to evaluate the best quality ice cream. The resistance to melting of the ice cream, is correlated with the formation of the fat network in the emulsion. In general, rice bran wax organogel ice creams had lower melting rates and better melting strength. The use of continuous freezing led to better structural stability than batch freezing in organogel formulations. The author does not make it clear whether the results are similar and compatible with formulations of ice cream prepared with milk fat but states that rice bran wax in high oleic sunflower oil presented promising results for application in ice cream. As structuring agent for organogels, the rice bran wax showed the most promising results in comparison to candelilla and carnauba, providing more stable ice cream with a lower percentage of melting and with a distribution of the size of emulsion particles which was more homogeneous compared to the characteristics of the ice cream used as control. (Botega et al., 2013).

\subsection{Cookies}

For this kind of product, organogels are used to replace shortenings. Shortening consists of a technical, crystallized and plasticized fat applied mainly in bakery products such as cakes, cookies and biscuits. Its main effect is to prevent the cohesion of gluten nets during mixing, and also plays a key role in the texture of these foods. In addition, it contributes positively to issues of stability and shelf-life of the products. As is well known, the conventional fats applied in this type of market also have high levels of saturated and/or trans fats. Some previous studies have applied vegetable oil to replace shortenings, but the final products lost their crispness, become greasier and their stability and shelf-life decreased, which justifies the use of organogels for these types of product (Jang et al., 2015).

Jang et al., (2015) investigated the organogels of candelilla wax $(3 \%$ and $6 \%$ ) in canola oil as a substitute for shortening in cookies. Regarding firmness tests, the authors reported that shortening fat had higher firmness values than the organogel samples. Organogels tended to be firmer with increasing levels of candelilla wax. The viscosity of all samples had a tendency to decrease non-linearly with increasing temperature. Organogels clearly exhibited higher viscosity values than shortening fat at temperatures between 50 and $70{ }^{\circ} \mathrm{C}$. Furthermore, it became clear that the viscosity of the organogels depended on the concentration of wax in the formulation. The rheology of the cookie dough was also evaluated for each formulation. The storage (G') and loss (G') modules tended to increase with increasing frequency. In addition, all samples presented higher values for G' than G', showing more elastic characteristics. The cookie dough prepared with shortening presented higher values for G' and G" compared to the samples prepared with organogel. These rheological properties can be attributed to the firmer texture of the shortening. The cookies prepared with organogel were also evaluated for their composition in fatty acids in comparison to the sample prepared with shortening. The percentage of total saturated and unsaturated fatty acids in shortening fat was $52.8 \%$ and $47.2 \%$, respectively. In the case of cookies prepared with organogel, the level of unsaturated fatty acids clearly increased to about $90-92 \%$ and the level of saturated fatty acids was reduced to $8-10 \%$. The predominant component in the cookies prepared with shortenings was palmitic acid (C16:0: 0.41.9\%), while samples prepared with organogel were rich in oleic $(\mathrm{C} 18: 1,62 \%)$, linoleic $(\mathrm{C} 18: 2,20 \%)$ and linolenic $(\mathrm{C} 18: 3,7 \%)$ acids, considered to be much healthier than the saturated fatty acids in shortening. Regarding the physical characteristics related to sensory, the authors reported that the low viscosity of the organogels in the temperature of the cookies contributed positively to their physical characteristics like snapping, which is breaking under a force applied to the cookie and is one of the most important physical attributes of cookies. According to the authors, the organogels showed promising results in replacing fats in cookies. However, they point out that a sensory evaluation will be necessary to investigate consumer preferences (Jang et al., 2015).

In 2016, Mert and Demirkesen also studied organogels (candelilla wax in canola oil) and pure canola oil as substitutes for shortenings in cookies. With the objective of reducing saturated fat, the authors studied both the total substitution of shortening as well as partial substitution with organogel making mixtures of organogel and shortenings. According to the results presented by the author, in an undisturbed state, both organogels and organogel/shortening blend formed structures with rheological properties comparable to pure shortening. However, the shear application rapidly transformed organogels and organogel/shortening blends into viscous liquids which lost their solid structures. They pointed out that the organogel/shortening mixtures with a greater amount of shortening improved the shear sensitivity of the samples proportionally. The experiments with dough samples showed that the ones containing organogel presented greater extensibility and lower hardness values than the samples prepared with shortening. Both of these are very important characteristics that will define the final texture of the product and its yield. The mixture of shortening with organogels resulted in dough samples with texture properties closer to the properties 
of the standard dough. When liquid oil was used in the formulation, the cookies had higher scattering proportions and hardness values. Although the incorporation of organogels improved the physical properties of the cookies compared to liquid oil, the functionality of the organogels was not sufficient to obtain quality parameters similar to shortening. On the other hand, the blends of shortening with organogels significantly improved the physical properties of cookies with up to $60 \%$ shortening fat reduction in the fat phase of the cookie. The results of this study indicated that the use of organogels improved the quality of cookies compared to cookies containing pure oil. A more conservative approach can be employed to reduce the saturated fat in baked goods. The partial substitution of shortening with organogels can produce much more acceptable properties for the dough and the cookie than total substitution (Mert and Demirkesen, 2016).

\subsection{Cakes}

In 2017, Kim and co-workers studied the application of organogels in cakes (aerated bakery product). According to them, specifically in aerated cakes and bakery products, solid fat plays an important role in generating the dough structure by trapping the air bubbles into the fatty phase of the cake dough. Therefore, the use of solid fat is important for the aeration of cooked cakes and interferes directly in its maximum volume (yield) and soft texture. However, the solid fat used mainly in industrial cakes is generally high in saturated fatty acids and may also contain trans fatty acids. The authors reported that there are only a few studies on the application of organogels in bakery products. Thus, they proposed a study to investigate the influence of organogels as a substitute for solid fat on the qualities of aerated products like cake. Different levels of shortening in cakes were replaced by canola organogels with carnauba wax and their effects on cake quality were examined in terms of physico-chemical, rheological and structural characteristics. They reported the existence of many studies looking at various types of oil such as soybean, canola, rapeseed, and safflower among others, in combinations with various waxes such as carnauba, candelilla, shellac and rice bran. However, they did not observe many studies with high oleic oils. According to the American Heart Association, the consumption of oils with high levels of oleic acid can reduce LDL cholesterol and consequently the risk of heart disease and stroke. In addition, foods prepared with oleic acid remain stable for consumption for longer periods, when compared to polyunsaturated oils, because of its greater oxidative stability, greater durability and also its use as a natural preservative. This motivated the authors to use canola oil and carnauba wax as a structuring agent for use as a substitute for fat in cakes. Physical, rheological, and structural characteristics were used as comparative features. The total shortening substitution by organogels negatively affected the rheological properties and density of the cake dough. However, no apparent differences were observed between the standard and the cakes by replacing the fat phase in the proportion of $25 \%$ organogel and $75 \%$ shortening, suggesting that the fatty phase in the cake formulation in these proportions could be used without loss in quality of the cake. In addition, replacing shortening with organogels could provide health benefits by decreasing the proportion of saturated fatty acids. For this mixture considered to be more promising (25\% organogel and $75 \%$ shortening) the reduction of saturated cake mass reached $10 \%$ in addition to the increase of $10 \%$ unsaturated fat. Therefore, the use of organogels as partial substitutes for cakes presents possible opportunities for producing healthier products with a significant reduction in saturated and trans-fat.

\subsection{Confectionery fillings}

In 2016, Doan and co-workers studied organogel with beeswax in rice bran oil as an alternative to palm oil in order to control the consumption of saturated fats in confectionery products, especially hazelnut fillings. The use of palm oil contributes to the taste and texture of the confectionery products due to its high content of saturated fatty acids (approximately 50\%). Mixtures of palm oil with organogel were obtained as an oil phase for application in the fillings. The palm oil was replaced with organogel in the proportions of 17,33 and $50 \%$ by weight. By replacing palm oil, the equivalence of the physicochemical properties of the new fat-based products, for example the solid state at room temperature and the melting behavior, are crucial for obtaining similar sensory and texture attributes of the derived products. In addition, the additional fat phase should not severely alter the crystallization or melting behavior of the palm oil, in cases where it is partially replaced. At body temperature, the solid mass fractions of palm and wax mixtures were less than $2.0 \%$, suggesting a non-waxy feeling in the mouth. The crystallization and melting temperatures of the palm blends and waxes were changed to lower temperatures due to the dilution effect when the palm oil was partially replaced with organogel. Interestingly, in spite of a lower melting enthalpy, the palm and organogel mixtures presented higher crystalline density and resistance when compared to reference samples (100\% palm). The authors indicated the efficiency of organogels from beeswax to rice bran oil as partial substitutes for palm oil. However, they were more conservative, suggesting a substitution of at most $17 \%$ of the palm oil since in this way it was possible to maintain a good property of taste and physical characteristics which were more similar to the reference sample (Doan et al., 2016). 


\section{CONCLUSIONS}

Organogels were tested as alternatives to replace saturated and trans-fats, thus producing healthier foods. The biggest challenge for researchers is to find an organogel that provides the same level of technological performance and versatility of solid fats for their applications, both in processing and sensory requirements. Waxes are among the most promising edible structuring agents for food organogels and their efficiency is sensitive and related to complex factors such as the chemical composition (origin) of both the wax and oil to be applied, as well as interactions with other structuring agents or ingredients where they are applied. These characteristics influence the structuring mechanisms, the shapes and sizes of the wax crystals, and consequently the texture and quality of the products where they are applied.

Among the most extensively studied waxes are from rice bran, sunflower, bees, candelilla, carnaúba and berry wax, they are the ones that result in the most stable and consistent organogels. Among the most promising applications are margarines, ice cream and cookies, with great potential for total replacement of conventional fat by organogels. Other applications such as cakes and confectionery have been studied with more conservative answers where partial substitution is recommended.

Many studies where the applications of these organogels of wax are presented prove their ability to totally or partially replace solid fats to obtain healthier products. Many challenges of application, production process, commercial viability and availability of these structuring agents need to be investigated, but the studies are in constant advance and this type of material is coming closer to arriving in the form of healthier foods to its consumers.

\section{ACKNOWLEDGMENTS}

The authors are grateful for the financial support of the Coordination for the Improvement of Higher Education Personnel (CAPES, Brazil).

\section{REFERENCES}

Almdal K, Dyre J, Hvidt S, Kramer O. 1993. Towards a phenomenological definition of the term 'gel'. Polym. Gels Networks 1, 5-17. https://doi.org/10.1016/0966-7822(93)90020-i

ANVISA (Agência Nacional de Vigilância Sanitária). 2003a. Resolucãa RDC no ${ }^{3}$ 39, de dezembro de 2003. Aprova o Regulamento Técnico de Porções de Alimentos Embalados para Fins de Rotulagem Nutricional. Diário Oficial da União, 26 de dezembro de 2003, Brasil.

ANVISA (Agência Nacional de Vigilância Sanitária). 2003b. Resolução RDC no.360, de dezembro de 2003. Aprova o Regulamento Técnico sobre Rotulagem Nutricional de Alimentos Embalados. Diário Oficial da União, 26 de dezembro de 2003, Brasil.

Banupriya S, Elango A, Karthikeyan N, Kathirvelan C. 2016. Physico Chemical Characteristics of Dietetic Ice Cream developed by with Sunflower Oil Rice Bran Wax
Organogel. Indian J. Sci. Technol. 9, e32. https://doi. org/10.17485/ijst/2016/v9i32/90771

Botega DCZ, Marangoni AG, Smith AK, Goff DH. 2013. The potential application of rice bran wax organogel to replace solid fat and enhance unsaturated fat content in ice cream. J. Food Sci. 78, 1334-1339. https://doi. org/10.1111/1750-3841.12175

Chaves KF, Barrera-Arellano D, Ribeiro APB. 2018. Potential application of lipid organogels for food industry. Food Res. Int. 105, 863-872. https://doi.org/10.1016/j.foodres.2017.12.020

Doan CD, To CM, Vrieze MD, Lynen F, Danthine S, Brown A, Dewettinck K, Patel AR. 2017. Chemical profiling of the major components in natural waxes to elucidate their role in liquid oil structuring. Food Chem. 214, 717-725. https:// doi.org/10.1016/j.foodchem.2016.07.123

Doan CD, Tavernier I, Sintang MDB, Danthine S, Van de Walle D, Rimaux T, Dewettinck K. 2016. Crystallization and gelation behavior of low- and high melting waxes in rice bran oil: a case-study on berry wax and sunflower wax. Food Biophys. 12, 97-108. https://doi.org/10.1007/s11483-016-9467-y

Godoi KRR, Basso RC, Buscato MHM, Cardoso LP, Kieckbusch TG, Ribeiro APB. 2107. Dispersed free phytosterols as structuring agents in lipid systems with reduced saturated fat. Grasas Aceites 68, e217. https://doi.org/10.3989/gya.0226171

Guedes PV. 2012. Caracterização reológica e ultraestrutural de géis produzidos à base de caseinomacropeptídeo. 135 f. Master thesis-Food Engenering, Paraná Federal University, Curitiba, PR. Available in: http://hdl.handle. net/1884/28720 Accessed in: 10 jan. 2018.

Hunter JE, Zhang J, Kris E, Penny M. 2009. Cardiovascular disease risk of dietary stearic acid compared with trans, other saturated, and unsaturated fatty acids: a systematic review. Am. $J$. Clin. Nutr 91, 46-63. https://doi.org/10.3945/aicn.2009.27661

Hwang HS, Singh M, Lee S. 2016. Properties of cookies made with natural wax-vegetable oil organogels. J. Food Sci. 81, 1045-1054. https://doi.org/10.1111/1750-3841.13279

Jang A, Woosung B, Hwang HS, Lee HG, Lee S. 2015. Evaluation of canola oil organogels with candelilla wax as an alternative to shortening in baked goods. Food Chem. 187, 525-529. https://doi.org/10.1016/j. foodchem.2015.04.110

Kanya TCS, Rao LJ, Sastry MCS. 2007. Characterization of wax esters, free fatty alcohols and free fatty acids of crude wax from sunflower seed oil refineries. Food Chem. 101, 15521557. https://doi.org/10.1016/j.foodchem.2006.04.008

Kim JY, Lim J, Lee J, Hwang HS, Lee S. 2017. Utilization of organogels as a replacement for solid fat in aerated baked goods: physicochemical, rheological, and tomographic characterization. J. Food Sc. 82, 445-452. https://doi. org/10.1111/1750-3841.13583

Kouzounis D, Lazaridou A, Katsanidis E. 2017. Partial replacement of animal fat by organogels structured with monoglycerides and phytosterols in frankfurter sausages. Meat Sci. 130, p.38-46. https://doi.org/10.1016/j.meatsci.2017.04.004

Marangoni A, Garti N. 2011. Edible Oleogels: Structure and Health Implications. AOCS Press, Urbana. https://doi. org/10.1016/C2015-0-02413-3

Mert B, Demirkesen I. 2016. Reducing saturated fat with organogel/shortening blends in a baked product. Food Chem. 199, 809-816. http://doi.org/10.1016/j.foodchem.2015.12.087

Oviedo KMM. 2010. Análise comparativa das experiências de regulação de gorduras trans em alimentos processados no Brasil, Canadá, Dinamarca e Estados Unidos. $141 \mathrm{f}$. PhD Thesis-PUC-RIO, Rio de Janeiro. https://doi. org/10.17771/PUCRio.acad.16328

Penteado AAT, Nogueira AC, Gandra KMB, Barrera-Arellano D, Steel CJ. 2018. Zero trans biscuits with soybean-based fats formulated using an artificial neural network. Grasas Aceites 69, e251. https://doi.org/10.3989/gya.1216172

Pernetti M, Malssen KFV, Flöter E, Bot A. 2007. Structuring of edible oils by alternatives to crystalline fat. Curr. Opin. Colloid Interface Sci. 12, 221-231. http://doi.org/10.1016/j. cocis.2007.07.002

Rogers MA, Wright AJ, Marangoni AG. 2009. Oil organogels: the fat of the future? Soft matter 5, 1594-1596. https://doi. org/10.1039/b822008p 
Singh A, Auzanneau F, Rogers MA. 2017. Advances in edible organogel technologies - a decade in review. Food Res. Int. 97, p. 307-317. https://doi.org/10.1016/j.foodres.2017.04.022

Sintang MDB, Danthine S, Patel AR, Rimaux T, Van De Wallee D, Dewettincka, K. 2017. Mixed surfactant systems of sucrose esters and lecithin as a synergistic approach for oil structuring. J. Colloid Interface Sci. 504, 387-396. https:// doi.org/10.1016/j.jcis.2017.05.114

Tavernier I, Doan CD, Van de Walle D, Danthine S, Rimaux T, Dewettinck K. 2017. Sequential crystallization of high and low melting waxes to improve oil structuring in waxbased organogels. RSC Adv. 7, 12113-12125. https://doi. org/10.1039/c6ra27650d

Terech P, Weiss RG. 1997. Low molecular mass gelators of organic liquids and the properties of their gels. Chem. Rev. 97, 3133-3159. https://doi.org/10.1021/cr9700282

Totosaus A, Gonzaléz-Gonzaléz R, Fragoso M. 2016. Influence of the type of cellulosic derivatives on the texture, and oxidative and thermal stability of soybean oil oleogel. Grasas Aceites 67, e152. https://doi.org/10.3989/ gya.0440161

Tulloch, AP. 1975. Chromatographic Analysis of natural waxes. Journal of Chromatographic Science 13, 403-407. https:// doi.org/10.1093/chromsci/13.9.403

USA. 2016. HHS and USDA release new dietary guidelines to encourage healthy eating patterns to prevent chronic diseases. USDA press: 202-720-4623. Available in: <https:// www.fns.usda.gov/pressrelease/2016/000516>. Accessed in: 07 jan. 2018.

Wang T, Rogers MA. 2015. Biomimicry - an approach to engineering oils into solid fats. Lipid Technol. 27, 175-178. https://doi.org/10.1002/lite.201500036

Yilmaz E, Oğütcü M. 2015. Organogels as spreadable fat and butter alternatives: sensory description and consumer perception. RSC Adv. 5, 50259-50267. https://doi.org/10.1039/ c5ra06689a 